\title{
Autumn-winter minimum temperature changes in the southern Sikhote-Alin mountain range of northeastern Asia since 1529 AD
}

\author{
Olga N. Ukhvatkina, Alexander M. Omelko, Alexander A. Zhmerenetsky, and Tatyana Y. Petrenko \\ Federal Scientific Center of the East Asia Terrestrial Biodiversity Far Eastern Branch of Russian Academy of Sciences, \\ Vladivostok 690022, Russia
}

Correspondence: Olga N. Ukhvatkina (ukhvatkina@gmail.com)

Received: 26 July 2017 - Discussion started: 14 August 2017

Revised: 22 November 2017 - Accepted: 5 December 2017 - Published: 16 January 2018

\begin{abstract}
The aim of our research was to reconstruct climatic parameters (for the first time for the Sikhote-Alin mountain range) and to compare them with global climate fluctuations. As a result, we have found that one of the most important limiting factors for the study area is the minimum temperatures of the previous autumnwinter season (August-December), and this finding perfectly conforms to that in other territories. We reconstructed the previous August-December minimum temperature for 485 years, from 1529 to 2014 . We found 12 cold periods (1535-1540, 1550-1555, 1643-1649, 1659-1667, 1675-1689, 1722-1735, 1791-1803, 1807-1818, 18221827, 1836-1852, 1868-1887, 1911-1925) and seven warm periods $(1560-1585,1600-1610,1614-1618,1738-1743$, 1756-1759, 1776-1781, 1944-2014). These periods correlate well with reconstructed data for the Northern Hemisphere and the neighboring territories of China and Japan. Our reconstruction has 3-, 9-, 20-, and 200-year periods, which may be in line with high-frequency fluctuations in $\mathrm{El}$ Niño-Southern Oscillation (ENSO), the short-term solar cycle, Pacific Decadal Oscillation (PDO) fluctuations, and the 200-year solar activity cycle, respectively. We suppose that the temperature of the North Pacific, expressed by the PDO may make a major contribution to regional climate variations. We also assume that the regional climatic response to solar activity becomes apparent in the temperature changes in the northern part of Pacific Ocean and corresponds to cold periods during the solar minimum. These comparisons show that our climatic reconstruction based on tree ring chronology for this area may potentially provide a proxy record for long-term, large-scale past temperature patterns for northeastern Asia. The reconstruction reflects the global traits and
\end{abstract}

local variations in the climatic processes of the southern territory of the Russian Far East for more than the past 450 years.

\section{Introduction}

Global climate change is the main challenge for human life and natural systems, which is why we should clearly understand climatic changes and their mechanisms. A retrospective review of climatic events is necessary for understanding the climatic conditions from a long-term perspective. At the same time, instrumental climate observations rarely cover more than a 100-year period and are often restricted to 50-70 years. This restriction forces the researchers to continuously find new ways and methods to reconstruct climatic fluctuations. Dendrochronology has been widely applied in climatic reconstruction for local territories and on the global scale for both climatic reconstructions of the past few centuries and paleoclimatic reconstructions because it is rather precise, extensively used, and a replicable instrument (Corona et al., 2010; Popa and Bouriaund, 2014; Kress et al., 2014; Lyu et al., 2016).

A great number of studies have focused on climatic change reconstruction for the northeastern parts of China based on $P$. koraiensis radial growth studies (e.g., Zhu et al., 2009; Wang et al., 2013, 2016; Zhu et al., 2015; Lyu et al., 2016). Climatic parameters were reconstructed for the whole Northern Hemisphere (Wilson et al., 2016) and China (Ge et al., 2016), and temperature characteristics were reconstructed for northeastern Asia (Ohyama et al., 2013). Despite this, there are very few studies of Russian Far Eastern climate (e.g., Willes et al., 2014; Jacoby et al., 2004; Shan et al., 2015); moreover, 
there is an absence of dendrochronological studies for the continental part of the Russian Far East. Meanwhile, most species present in northeastern China, the Korean peninsula, and Japan grow in this region. In addition, the distribution areas of these trees often end in the south of the Russian Far East, which increases the climatic sensitivity of plants. Additionally, some parts of the forests in the Russian Far East have not been subjected to human activity for the last 20004000 years. This makes it possible for forests to extend the studied timespan. In addition, the southern territory of the Russian Far East is sensitive to global climatic changes as it is under the influence of cold air flow from northeastern Asia during the winter and summer monsoons. All of the factors listed above create favorable conditions for dendroclimatic studies.

It is well known that cold and warm periods of the climate are correlated with intensive solar activity (e.g., the Medieval Warm Period), while decreases in temperature occur during periods of low solar activity (e.g., the Little Ice Age; Lean and Rind, 1999; Bond et al., 2001). According to findings from an area of China neighboring the territory studied here, the registered warming has been significantly affected by global warming since the 20th century (Ding and Dai, 1994; Wang et al., 2004; Zhao et al., 2009), which is often indicated by a faster rise in night or minimum temperatures (Karl et al., 1993; Ren and Zhai, 1998; Tang et al., 2005). To better understand and evaluate future temperature change trends, we should study the long-term history of climatic changes.

However, using tree ring series for northeastern Asia (particularly temperature) is rather complicated due to the unique hydrothermal conditions of the region. Most reconstructions cover periods of less than 250 years (e.g., Shao and Wu, 1997; Zhu et al., 2009; Wang et al., 2012; Li and Wang, 2013; Yin et al., 2009; Zhu et al., 2015), except for a few with periods of up to 400 years (Lyu et al., 2016; Wiles et al., 2014). The short period of reconstructions is the reason why such reconstructions cannot capture low-frequency climate variations.

The warming of the climate (particularly minimum temperature increase) is registered across the whole territory of northeastern Asia (Lyu et al., 2016). In the Russian Far East, such warming has been recorded for more than 40 years (Kozhevnikova, 2009). However, the lack of detailed climatic reconstructions for the last few centuries makes it difficult to capture long climatic events for this territory and interpret the temperature conditions for the last 500-1000 years.

Therefore, the main objectives of this study were (1) to develop the first three-ring-width chronology for the southern part of the Russian Far East; (2) to analyze the regime of temperature variation over the past centuries in the southern part of the Russian Far East; and (3) to identify the recent warming amplitude in context of long-term changes and to analyze the periodicity of climatic events and their driving forces. Our new minimum temperature record supplements the existing data for northeastern Asia and provides new ev-

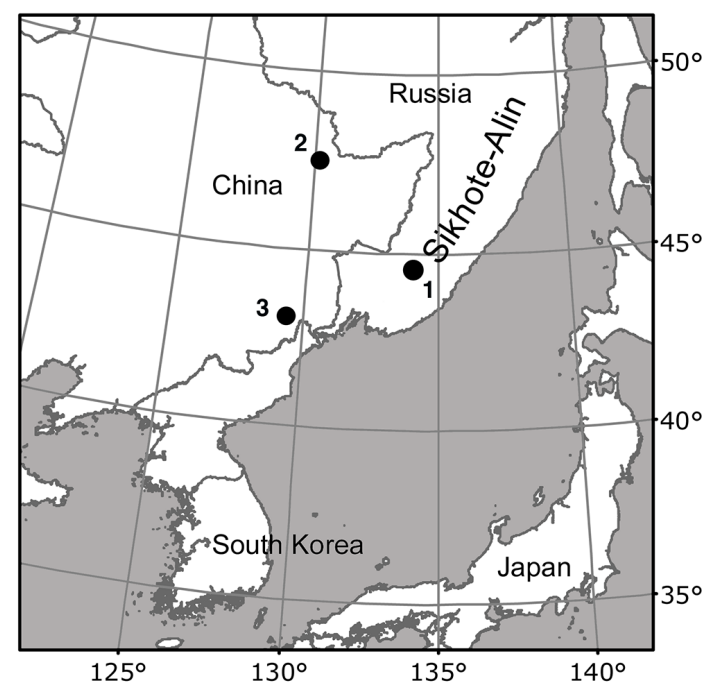

Figure 1. Location of the study area in the Sikhote-Alin Mountains, southeastern Russia (1), and sites of compared temperature reconstructions: April-July minimum temperature on Laobai Mountain by Lyu et al. (2016) (2) and February-April temperature established by Zhu et al. (2009) in the Changbai Mountains (3).

idence of past climate variability. There is the potential to better understand future climatic trajectories from these data in northeastern Asia.

\section{Materials and methods}

\subsection{Study area}

We studied the western macroslope of the southern part of the Sikhote-Alin mountain range (southeastern Russia) at the Verkhne-Ussuriysky research station of the Federal Scientific Center of the East Asia Terrestrial Biodiversity Far Eastern Branch of the Russian Academy of Sciences (4400 ha; $44^{\circ} 01^{\prime} 35.3^{\prime \prime} \mathrm{N}, 134^{\circ} 12^{\prime} 59.8^{\prime \prime} \mathrm{E}$, Fig. 1).

The territory is characterized by a monsoon climate with relatively long, cold winters and warm, rainy summers (Fig. 2). The average annual air temperature is $0.9^{\circ} \mathrm{C}$; January is the coldest month $\left(-32^{\circ} \mathrm{C}\right.$ average temperature), and July is the warmest month $\left(27^{\circ} \mathrm{C}\right.$ average temperature). The average annual precipitation is $832 \mathrm{~mm}$ (Kozhevnikova, 2009). Southerly and southeasterly winds predominate during the spring and summer, while northerly and northwesterly winds predominate in autumn and winter. The terrain includes mountain slopes with an average angle of $\sim 20^{\circ}$, and the study area is characterized by brown mountain forest soils (Ivanov, 1964).

Mixed forests with Korean pine (Pinus koraiensis Siebold et Zucc.) are the main vegetation type in the study area, and they form an altitudinal belt up to $800 \mathrm{~m}$ above sea level. These trees are gradually replaced by coniferous fir-spruce forests at high altitudes (Kolesnikov, 1956). Korean pine- 


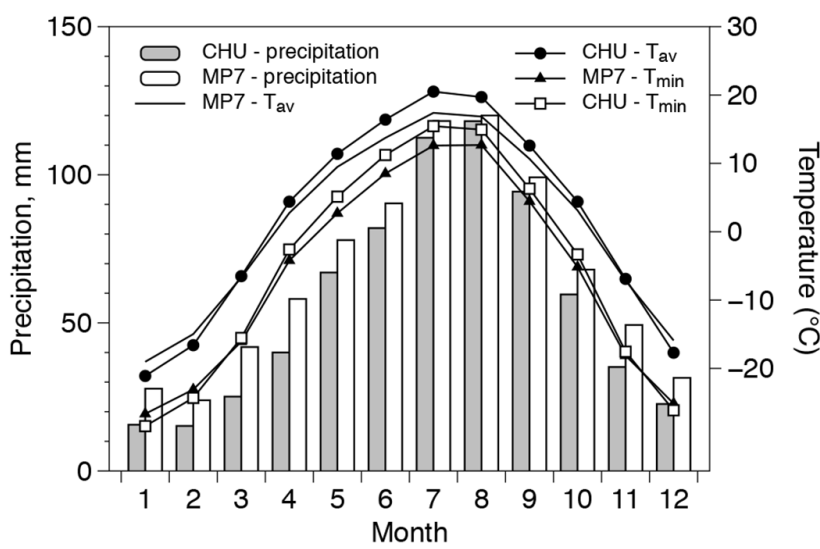

Figure 2. Mean monthly (1936-2004) and minimum temperature (1971-2003) and total precipitation (1936-2004) at Chuguevka and mean monthly and minimum temperature and total precipitation for VUS meteorological station (MP7; 1966-2000).

broadleaved forests are formed by up to 30 tree species, with Abies nephrolepis (Trautv.) Maxim, Betula costata (Trautv.) Regel., Picea jezoensis (Siebold et Zucc.) Carr., P. koraiensis and Tilia amurensis Rupr. being dominant.

Korean pine-broadleaved forests are the main forest vegetation type in the Sikhote-Alin mountain range in the southern part of the Russian Far East. This area is the northeastern limit of the range of Korean pine-broadleaved forests, which are also found in northeastern China (the central part of the range), on the Korean peninsula, and in Japan. The SikhoteAlin mountain range is one of the few places where significant areas of old-growth Korean pine-broadleaved forest remain. In the absence of volcanic activity, which is a source of strong natural disturbances in the central part of the range (Liu, 1997; Ishikava, 1999; Dai et al., 2011), wind is the primary disturbance factor in this territory. Wind causes a wide range of disturbance events, from individual tree falls to large blowdowns (Dai et al., 2011).

Approximately $60 \%$ of the research station area had been subjected to selective clear-cutting before the station was established in 1972. The remaining $40 \%$ of its area has never been clear-cut and is covered by unique old-growth forest.

\subsection{Tree ring chronology development}

Our study is based on data collected in a 10.5 ha permanent plot (Omelko and Ukhvatkina, 2012; Omelko et al., 2016), which was located in the middle portion of a western-facing slope with an angle of $22^{\circ}$ at a gradient altitude 750-950 ma.s.l. The forest in the plot was a latesuccessional stand belonging to the middle type of Korean pine-broadleaved forests at the upper bound of the distribution of Korean pine, where it forms mixed stands of Korean pine-spruce and spruce-broadleaved forests (Kolesnikov, 1956).
One core per undamaged old-growth mature tree ( 25 cores from 25 trees) and one sample from dead trees (20 samples) were extracted from $P$. koraiensis trees in the sample plots from the trunks at breast height. In the laboratory, all tree ring samples were mounted, dried, and progressively sanded to a fine polish until individual tracheids within annual rings were visible under an anatomical microscope according to standard dendrochronological procedures (Fritts, 1976; Cook and Kairiukstis, 1990). Preliminary calendar years were assigned to each growth ring, and possible errors in measurement due to false or locally absent rings were identified using the skeleton-plot cross-dating method (Stokes and Smiley, 1968). The cores were measured using the semiautomatic Velmex measuring system (Velmex, Inc., Bloomfield, NY, USA) with a precision of $0.01 \mathrm{~mm}$. Then, the COFECHA program was used to check the accuracy of the cross-dated measurements (Holmes, 1983). To mitigate the potential trend distortion problem in traditionally detrended chronology (Melvin and Briffa, 2008; Anchukaitis et al., 2013), we used a signal-free method (Melvin and Briffa, 2008) to detrend the tree ring series using the RCSigFree program (http://www.ldeo.columbia.edu/ tree-ring-laboratory/resources/software).

Age-related trends were removed from the raw tree ring series using an age-dependent spline smoothing method. The ratio method was used to calculate tree ring indices, and the age-dependent spline was selected to stabilize the variance caused by core numbers. Finally, the stabilized signal-free chronology was used for the subsequent analysis (Fig. 3). The mean correlations between trees $(R \mathrm{bt})$, mean sensitivity (MS), and expressed population signal (EPS) were calculated to evaluate the quality of the chronology (Fritts, 1976). $R$ bt reflects the high-frequency variance, and MS describes the mean percentage change from each measured annual ring value to the next (Fritts, 1976; Cook and Kairiukstis, 1990). EPS indicates the extent to which the sample size is representative of a theoretical population with an infinite number of individuals. A level of 0.85 in the EPS is considered to indicate a chronology of satisfactory quality (Wigley et al., 1984). The statistical characteristics of the chronology are listed in Table 1.

The full length of the chronology spans (VUS chronology) from 1451 to 2015. A generally acceptable threshold of the EPS was consistently greater than 0.85 from AD 1602 to 2015 (nine trees; Fig. 3b), which affirmed that this is a reliable period. However, although the EPS value from AD 1529 to 1602 was less than 0.85 , it matches a minimum sample depth of four trees in this segment (EPS $>0.75$ ). Although the record from AD 1529 to 1602 is thus less certain, here we report it as it is very important to extend the tree ring chronology as much as possible because there are only a few long climate reconstructions in this area. Therefore, we retained the part from 1529 to 1602 in the reconstruction. 


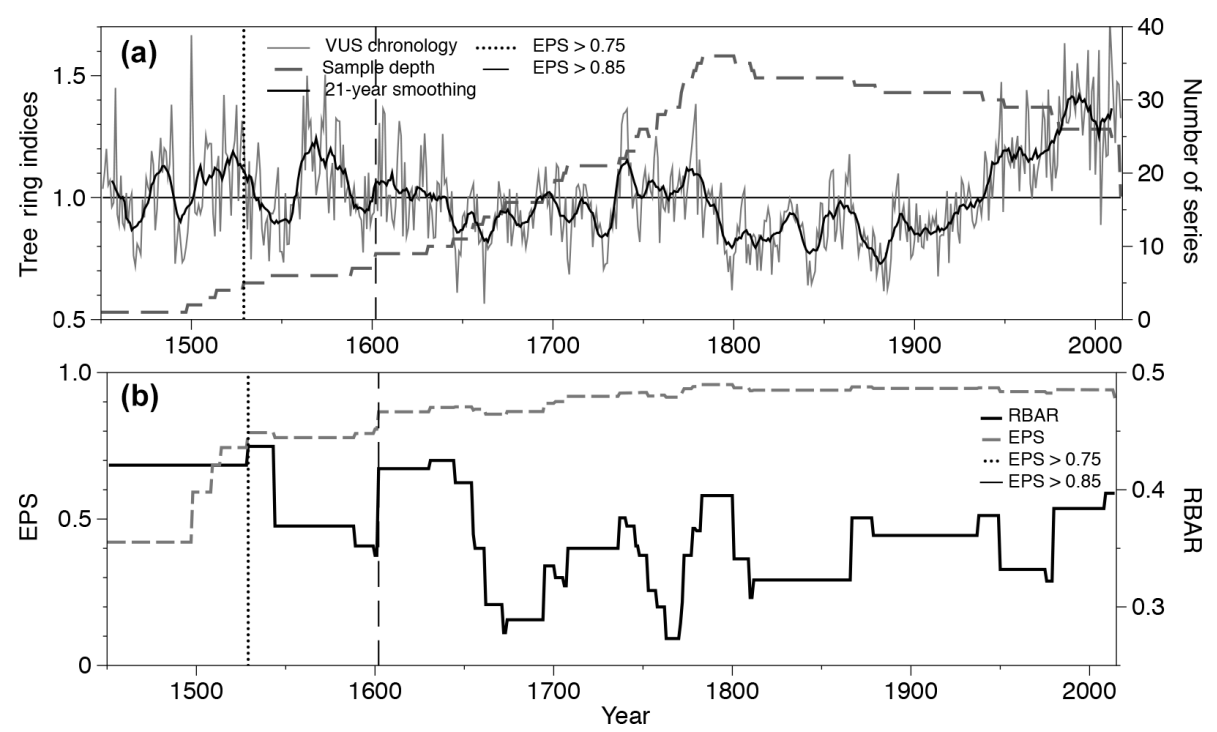

Figure 3. Variations in the VUS chronology and sample depth (a) and the expressed population signal (EPS) and average correlation between all series (Rbar) VUS chronology from AD 1451 to 2014 (b).

Table 1. The sampling information and statistics of the signal-free chronology.

\begin{tabular}{lr}
\hline & VUSr \\
\hline Elevation (m a.s.1.) & $700-900$ \\
Latitude (N), longitude (E) & $44^{\circ} 01^{\prime} 32^{\prime \prime} \mathrm{N} 134^{\circ} 13^{\prime} 15^{\prime \prime} \mathrm{E}$ \\
Core (live trees)/sample & $25 / 20$ \\
(dead trees) & \\
Time period/length (year) & $1451-2014 / 563$ \\
MS & 0.253 \\
SD & 0.387 \\
AC1 & 0.601 \\
$R$ & 0.691 \\
EPS & 0.952 \\
Period with EPS $>0.85 / l e n g t h$ & $1602-2014 / 412$ \\
(year) & \\
Period with EPS $>0.75 /$ length & $1529-2014 / 485$ \\
(year) & \\
Skew/kurtosis & $0.982 / 5.204$ \\
\hline
\end{tabular}

MS - mean sensitivity; SD - standard deviation; AC1 - first-order autocorrelation; EPS - expressed population signal.

\subsection{Climate data and statistical methods}

Monthly precipitation, monthly mean, and minimum temperature data were obtained from the Chuguevka meteorological station $\left(44.151462^{\circ} \mathrm{N}, 133.869530^{\circ} \mathrm{E}\right.$, about $30 \mathrm{~km}$ from Verkhne-Ussuriisky research station) and the meteorological post at the Verkhne-Ussuriisky research station of the Federal Scientific Center of the East Asia Terrestrial Biodiversity Far Eastern Branch of the Russian Academy of Sciences (Meteostation 7 - MP7) as well. The periods of monthly data available from the Chuguevka and Verkhne-Ussuriisky stations are 1936-2004 and 1969-2004, respectively (19712003 for minimum temperature data from the Chuguevka).

The data of large-scale climate conditions, such as the Northern Hemisphere temperature, North Atlantic Oscillation (AMO), Pacific Decadal Oscillation (PDO), and Nino3 reconstruction (Mann et al., 2009), and also indicators of solar activity, such as reconstructed solar constant (total solar irradiation, TSI; Lean, 2000) and sun spot number (SSN), were downloaded and analyzed in Royal Netherlands Meteorological Institute climate explorer (http://climexp.knmi.nl).

To demonstrate that our reconstruction is representative and reflects temperature variations, we conduced spatial correlation between our temperature reconstruction and the gridded temperature data set of the Climate Research Unit (CRU TS4.00) for the period 1960-2003, by using the Royal Netherlands Meteorological Institute climate explorer (http: //climexp.knmi.nl).

\subsection{Statistical analyses}

A correlation analysis was used to evaluate the relationships between the ring-width index and observed monthly climate records from the previous June to the current September. To identify the climate-growth relationships of Korean pine in the southern Sikhote-Alin mountain range, a Pearson's correlation was performed between climate variables and treewidth index. We used a traditional split-period calibration and verification method to explore the temporal stability and reliability of the reconstruction model (Fritts, 1976; Cook and Kairiukstis, 1990). The Pearson's correlation coefficient $(r), R$ squared $\left(R^{2}\right)$, the redaction of the error (RE) the coefficient of efficiency (CE), and the product means test were used to verify the results. Analyses were carried out in R us- 
ing the treeclim package (Zang and Biondi, 2015) and STATISTICA software $\left(\mathrm{StatSoft}^{\circledR}\right)$. Analyses of reconstruction included the multi-taper method (MTM; Mann and Lees, 1996) and Monte Carlo singular spectrum analysis (SSA; Allen and Smith, 1996). Analysis was carried out in SSAMTM Toolkit for Spectral Analysis software (Ghil et al., 2001; Dettinger et al., 1995).

\section{Results}

\subsection{Climate-radial growth relationship}

Relationships between the VUS chronology and monthly climate data are shown in Fig. 4. To reveal the correlation between climatic parameters and radial growth change of $P$. $k o-$ raiensis, we had three data sets: the first time series had a length of 68 years (1936-2004, Chuguevka), the second had a length of 34 years (1966-2000, MP7), and the third had a length of 33 years (1971-2003, Chuguevka, minimum temperature). To select the appropriate parameters, we analyzed all data sets. As a result, we revealed a reliable but slight positive correlation between $P$. koraiensis growth and precipitation in May and June of the current year and September of the previous year in the territory of Chuguevka village (Fig. 4a). There is also a slight positive correlation with precipitation in September of the previous year and May of the current year at MP7 (Fig. 4b). In addition, we revealed a slight negative correlation with precipitation in February-March of the current year.

As for the correlation between temperature and $\mathrm{P}$. koraiensis growth, the analysis reveals a weak positive correlation with the average monthly temperature in June of the previous year and in February-April of the current year in the Chuguevka settlement and a slight negative correlation with the average monthly temperature in June-July as well (Fig. 4c). The analysis of the correlation with the average monthly temperature at MP7 shows us a weak positive correlation with temperature in August and December of the preceding year and a negative correlation with temperature in July of the current year (Fig. 4d). In addition, we analyzed the correlation with minimum average monthly temperatures at MP7 and Chuguevka. The revealed correlation with minimum temperature is reliable but weak (Fig. 4e, f).

Moreover, based on the weak interaction that was revealed, we analyzed the correlation with climatic parameters for selected ranges of months (Fig. $4 \mathrm{~h}, \mathrm{~g}$ ). The highest significant correlation appears between growth and the minimum monthly temperature of August-December of the previous year at Chuguevka (Fig. 4h), on which we base our subsequent reconstructions.

\subsection{Minimum temperature reconstruction}

Based on analysis of the correlation between climatic parameters and Korean pine growth, we constructed a linear regres-
Table 2. Calibration and verification statistics of the reconstruction equation for the common period 1971-2003 of bootstrap.

\begin{tabular}{lrr}
\hline Statistical item & Calibration & $\begin{array}{r}\text { Verification (bootstrap, } \\
199 \text { iterations) }\end{array}$ \\
\hline$r$ & 0.62 & $0.62(0.54-0.70)$ \\
$R^{2}$ & 0.39 & $0.39(0.37-0.41)$ \\
$R_{\text {adj }}^{2}$ & 0.36 & $0.37(0.37-0.40)$ \\
Standard error & 1.20 & 1.11 \\
of estimate & & \\
$F$ & 18.76 & 18.54 \\
$P$ & 0.0001 & 0.0001 \\
Durbin-Watson & 1.73 & 1.80 \\
\hline
\end{tabular}

sion equation to reconstruct the minimum monthly temperature of August-December of the previous year (VUSr). The transfer function was as follows:

$$
\begin{aligned}
& \text { VUSr }=7.189 X_{t}-15.161 \\
& \left(N=32, R=0.620, R^{2}=0.385, R_{\text {adj }}^{2}=0.364,\right. \\
& F=18.76, p<0.001)
\end{aligned}
$$

where VUSr is the August-December minimum temperature at Chuguevka and $X$ is the tree ring index of the Korean pine chronology in year $t$. The comparison between the reconstructed and observed mean growing season temperatures during the calibration period is shown in Fig. 5a. The cross-validation test for the calibration period (1971$1997, R=0.624$ ) yielded a positive RE of 0.334 and a CE of 0.284 ; the cross-validation test for the calibration period $1977-2003(R=0.542)$ yielded a positive RE of 0.654 and a CE of 0.644, confirming the predictive ability of the model. Although during the study period the model shows the observed values very well, the short observation period (19712003) does not allow the use of split-sampling calibration and verification methods in full for evaluating quality and model stability. This limitation is why we used a bootstrapping resampling approach (Efron, 1979; Young, 1994) for stability evaluation and transfer function precision. The idea that this method is based on indicates that the available data already include all the necessary information for describing the empirical probability for all statistics of interest. Bootstrapping can provide the standard errors of statistical estimators even when no theory exists (Lui et al., 2009). The calibration and verification statistics are shown in Table 2 . The statistical parameters used in bootstrapping are very similar to those from the original regression model, and this proves that the model is quite stable and reliable and that it can be used for temperature reconstruction. 


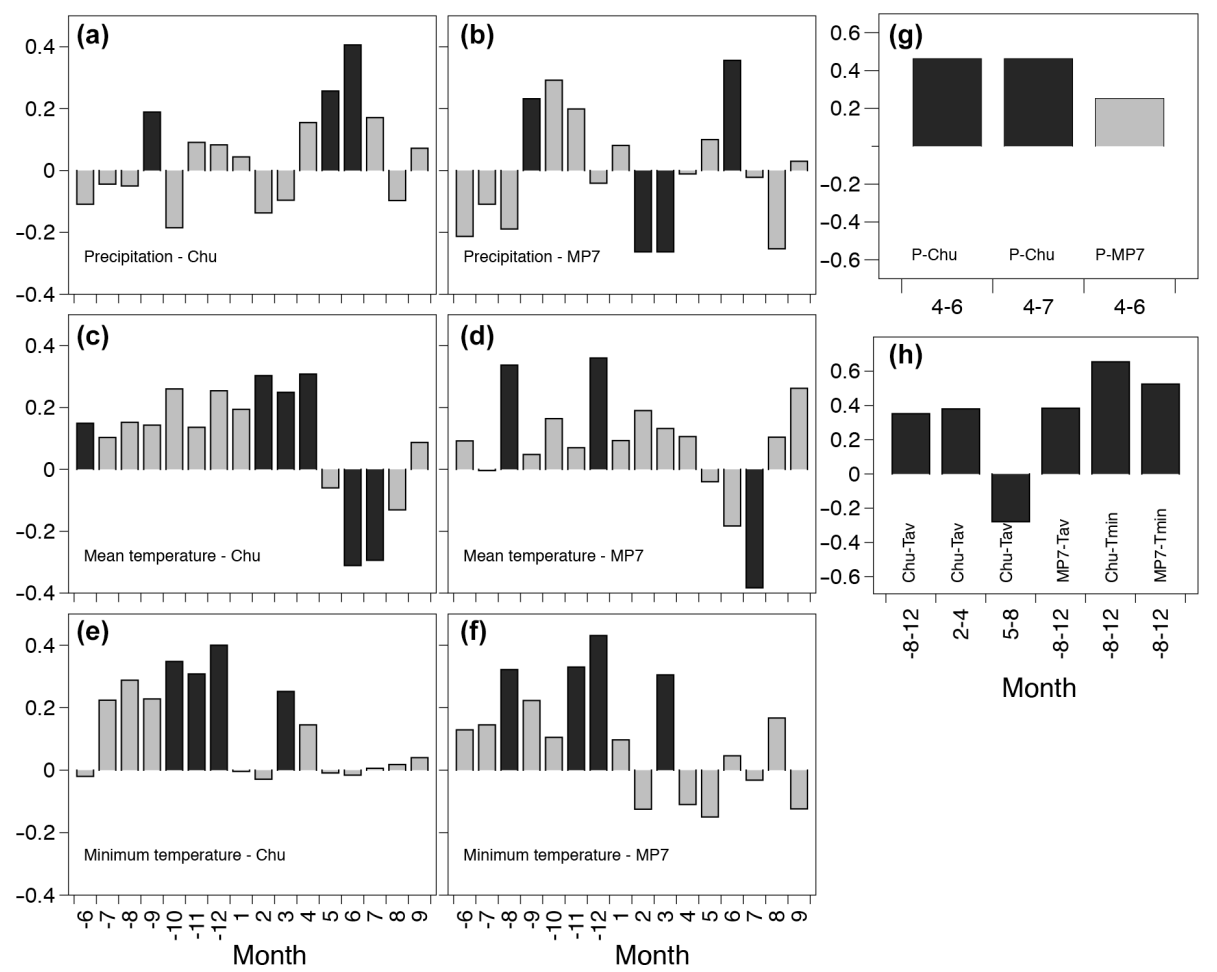

Figure 4. Correlations between the monthly mean meteorological data and VUS chronology. (a, c, e) Chuguevka (Chu) and VUS chronology; (b, d,f) VUS meteorological station (MP7) and VUS chronology; (g) correlation coefficients between VUS chronology and the precipitation of different month combinations; (h) correlation coefficients between VUS chronology and the temperature of different month combinations. The black bars are significant values.

\subsection{Temperature variations from AD 1529 to 2014 and temperature periodicity}

Variations in the reconstructed average minimum temperature of the previous August-December (VUSr) since AD 1529 and its 21-year moving average are shown in Fig. 5b. The 21-year moving average of the reconstructed series was used to obtain low-frequency information and analyze temperature variability in this region. The mean value of the 486-year reconstructed temperature was $-7.93^{\circ} \mathrm{C}$ with a standard deviation of $\pm 1.40^{\circ} \mathrm{C}$. We defined warm and cold periods as when temperature deviated from the mean value plus or minus 0.5 times the standard deviation, respectively (Fig. 5b). If the reconstructed minimum temperatures were above or below the average value by $>0.5 \mathrm{SD}$ for three or more years, then we considered this deviation to be a warm or cold period, respectively. Also, if two warm (or cold) periods were separated by 1 year, when the temperature sharply decreased (or increased), then such periods were merged into one.

Hence, warm periods occurred in 1560-1585, 1600-1610, 1614-1618, 1738-1743, 1756-1759, 1776-1781, and 19442014, and cold periods appeared in 1535-1540, 1550-1555, 1643-1649, 1659-1667, 1675-1689, 1722-1735, 17911803, 1807-1818, 1822-1827, 1836-1852, 1868-1887, and
1911-1925. Among them, the seven warmest years were in $1574\left(-4.35^{\circ} \mathrm{C}\right), 1606\left(-5.35^{\circ} \mathrm{C}\right), 1615\left(-5.71^{\circ} \mathrm{C}\right)$, $1741\left(-5.36^{\circ} \mathrm{C}\right), 1757\left(-6.16^{\circ} \mathrm{C}\right), 1779\left(-5.21^{\circ} \mathrm{C}\right), 2008$ $\left(-2.72^{\circ} \mathrm{C}\right)$, while the 12 coldest years were in 1543 $\left(-9.84^{\circ} \mathrm{C}\right), 1551\left(-9.88^{\circ} \mathrm{C}\right), 1647\left(-10.77^{\circ} \mathrm{C}\right), 1662$ $\left(-11.10^{\circ} \mathrm{C}\right), 1685\left(-9.45^{\circ} \mathrm{C}\right), 1728\left(-10.08^{\circ} \mathrm{C}\right), 1799$ $\left(-10.70^{\circ} \mathrm{C}\right), 1815\left(-10.13^{\circ} \mathrm{C}\right), 1825\left(-9.87^{\circ} \mathrm{C}\right), 1843$ $\left(-10.55^{\circ} \mathrm{C}\right), 1883\left(-10.73^{\circ} \mathrm{C}\right)$, and $1913\left(-10.29^{\circ} \mathrm{C}\right)$. The longest cold period extended from 1868 to 1887 , and the longest warm period extended from 1944 to present day. The coldest year is $1662\left(-11.10^{\circ} \mathrm{C}\right)$ and the warmest year is $2008\left(-2.72^{\circ} \mathrm{C}\right)$.

The MTM spectral analysis over the full length of our reconstruction revealed significant $(p<0.05)$ cycle peaks at 2.3-year (95\%), 2.5-year (99\%), 2.9-year (99\%), 3.0year $(99 \%), 3.3$-year $(95 \%), 3.7$-year $(95 \%)$, and 8.9-year (99\%) short periods and 20.4-year (95\%), 47.6-year (95\%), and 188.7-year (99\%) long periods (Fig. 6). SSA reveals eight leading temporal modes that are significant at the $95 \%$ confidence level (Allen and Smith, 1996). Of these, SSA analysis reveals a single significant low-order mode variability near 200 years, but there is little evidence in the reconstruction variability at $40-50$ years. Also, three significant power periods were revealed: 20.4-year, 9-year, and near-3-year periods. Comparison of the reconstruction 


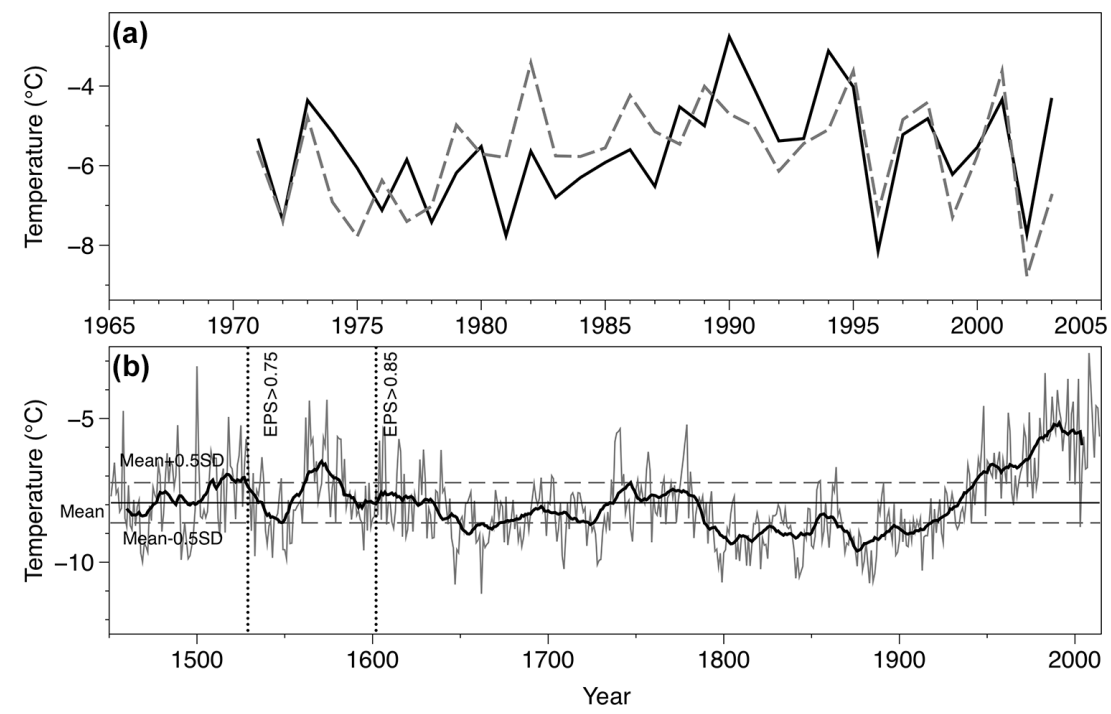

Figure 5. (a) Actual (black line) and reconstructed (dash line) August-December minimum temperature for the common period of 19712003; (b) reconstruction of August-December minimum temperature (VUSr) for the southern part of Sikhote-Alin for the last 563 years. The smoothed line indicates the 21-year moving average.

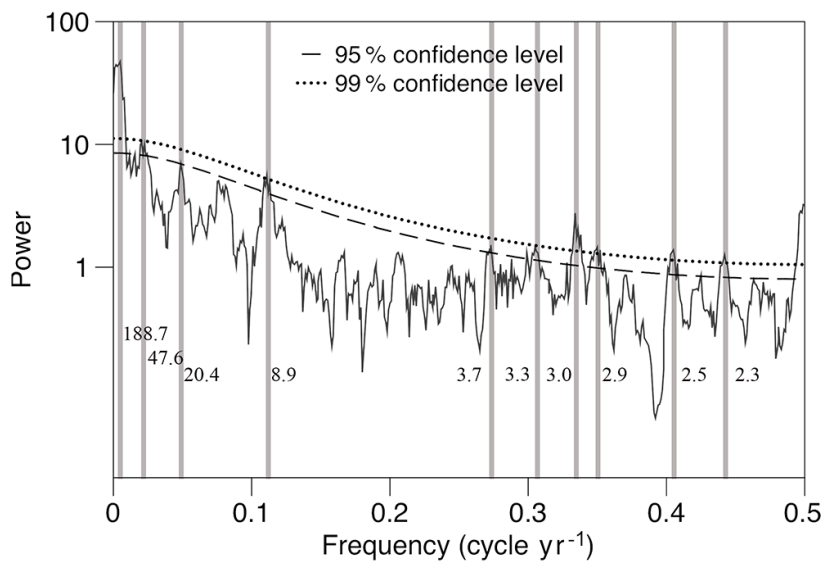

Figure 6. The MTM power spectrum of the reconstructed AugustDecember minimum temperature (VUSr) from 1529 to 2014.

and global temperature for oceans of the Northern Hemisphere, AMO, PDO, and Nino3 reconstruction (Mann et al., 2009) show significant correlation among the reconstruction and the Northern Hemisphere $(r=0.67, p<0.0001)$, $\operatorname{AMO}(r=0.49, p<0.001)$, and PDO $(r=0.68, p<0.0001)$, and nonsignificant correlation between reconstruction and the Nino3 reconstruction $(r=0.27, p=0.08)$. Comparison of the reconstruction and indicators of solar activity shows significant correlation of the minimum temperature with the TSI $(r=0.52, p<0.0001)$ and nonsignificant correlation with SSN $(r=0.26, p<0.1)$. Comparison of the instrumental climate data and instrumental indicators of solar activity shows significant correlation of the minimum temperature with the TSI $(r=0.52, p<0.0001)$ and nonsignificant correlation with $\operatorname{SSN}(r=0.26, p<0.1)$.

Spatial correlations between our reconstruction and the CRU TS4.00 temperature data set reveal our record's geographical representation (Fig. 7). The results show that the reconstruction of mean minimum temperature from the previous August-December is significantly positively correlated with the CRU TS4.00 $(r=0.568, p<0.0001)$.

\section{Discussion}

\subsection{Climate-growth relationships}

The results of our analysis suggest that the radial growth of Korean pine in the southern part of the Sikhote-Alin mountain range is mainly limited by the pre-growth autumnwinter season temperatures, in particular the minimum temperatures of August-December (Fig. 4). It is widely known that tree ring growth in cold and wet ecotopes, situated on sufficiently high elevation in the Northern Hemisphere, strongly correlate with temperature variability in large areas of Asia, Eurasia, and North America (Zhu et al., 2009; Anchukaitis et al., 2013; Thapa et al., 2015; Wiles et al., 2014). The limiting influence of temperature on P. koraiensis growth has been mentioned in many studies (Wang et al., 2013, 2016; Yin et al., 2009; Zhu et al., 2009). However, the temperature has various limiting effects in different conditions, and these limiting effects manifest in different ways (Wang et al., 2016). For example, Zhu et al. (2016) indicate that in the more northern and arid conditions of the Zhangguangcai Mountains, while precipitation is not the main limiting factor, precipitation is considerably lower than evaporation during the growth season. This finding is why a stable 

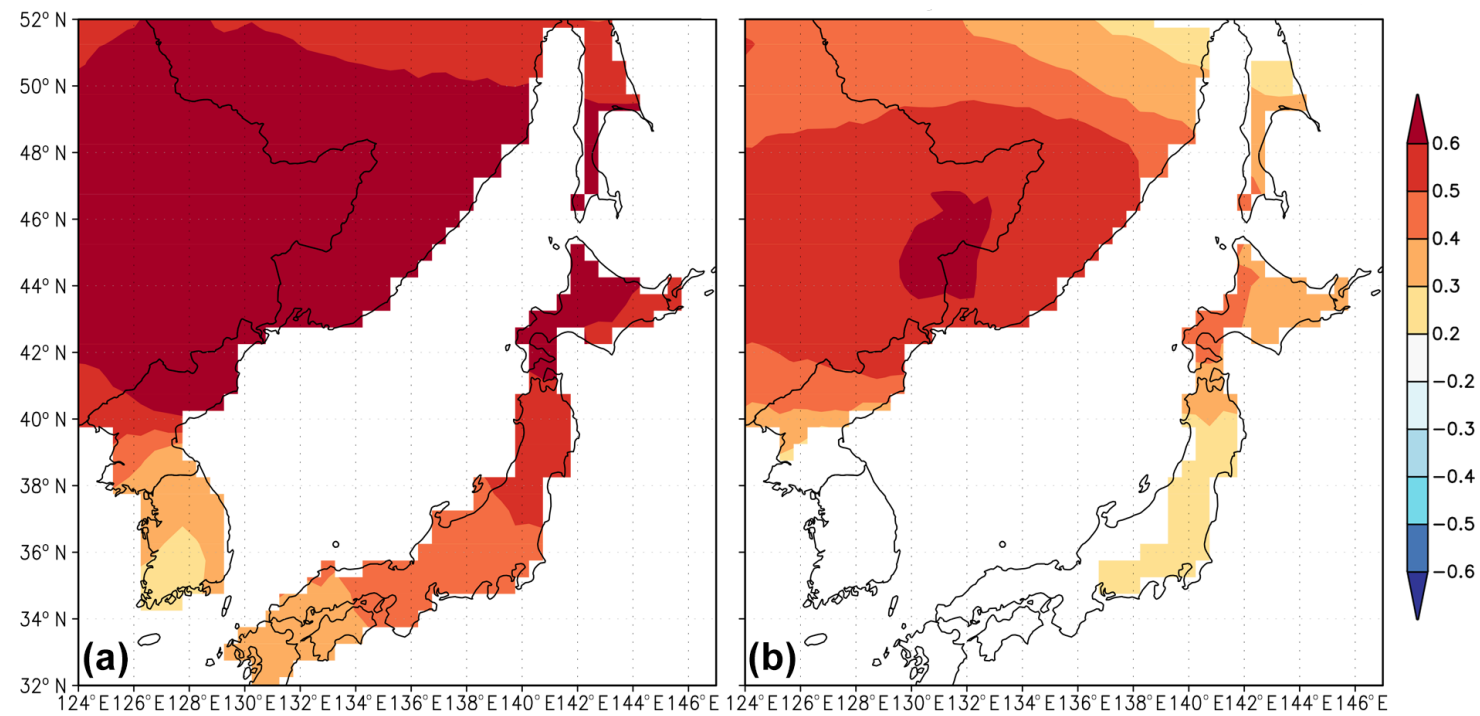

Figure 7. Spatial correlations between the observed (a) and reconstructed (b) August-December minimum temperature (VUS) in this study and regional gridded annual minimum temperature from CRU TS 4.00 over their common period of 1960-2003 ( $p<10 \%)$.

correlation between $P$. koraiensis growth and the growth season temperature is revealed. This finding is also why moisture availability in soil might be the main limiting factor for Korean pine growth (Zhu et al., 2016), but the emergence of this circumstance can be different in different conditions.

The correlation between growth and minimum temperatures in August-December of the previous year, as revealed in our research, was also mentioned for Korean pine in other works (Wang et al., 2016; Zhang et al., 2015). This finding may be explained by the following circumstances. Extreme temperatures limit the growth of trees at the tree line or in high-latitude forests (Wilson and Luckman, 2002; Körner and Paulsen, 2004; Porter et al., 2013; Yin et al., 2015). Taking into consideration the fact that the study area is situated at the altitudinal limit of Korean pine forest distributions, in particular the Korean pine (Kolesnikov, 1956), these findings seem to be reliable.

In addition, in the conditions close to extreme for this species, low temperatures in autumn-winter may lead to thicker snow cover, which melts far more slowly in spring (Zhang et al., 2015). The study area is notable for its dry spring, and the amount of precipitation is minimal during the most important period of tree growth in April-May (Kozhevnikova, 2009). If the vegetation period of the plant cannot begin at the end of March and packed snow cover melting is impeded up until the beginning of May, plant growth may be reduced. Moreover, although cambial activity stops in the winter, organic components are still synthesized by photosynthesis. Low temperatures (in the territory of the VUSr it can reach $-48^{\circ} \mathrm{C}$ in certain years) may induce a loss of accumulated materials, which adversely affects growth (Zhang et al., 2015). The study area is in the center of the vegetated area, where the conditions for Korean pine growth are optimal during the growing season, and only minimum temperature is regarded as an extreme factor.

\subsection{Comparison with other tree-ring-based temperature reconstructions}

At present, temperature reconstructions are uncommon for the Russian Far East, and research sites are located thousands of kilometers away from one another. For example, Wiles et al. undertook a study of summer temperatures on Sakhalin Island (Wiles et al., 2014). Unfortunately, it is impossible to compare our findings with theirs because Sakhalin Island is climatically far more similar to Japanese islands than to the Sikhote-Alin mountains, and temperature variations in their study area are mainly caused by oceanic currents.

In addition, instrumental observations from the study area rarely encompass a period longer than 50 years (and studies have only been conducted for large settlements). Consequently, the tree ring record serves as a good indicator of the past cold-warm fluctuations in the Russian Far East. The analysis of spatial correlations between our reconstruction and the CRU TS4.00 temperature data set reveals spatial correlations between the observed and reconstruction minimum temperatures from the CRU TS4.00 gridded $T_{\min }$ data set during the baseline period of 1960-2003 (Fig. 7). This indicates that our temperature reconstruction is representative of large-scale regional temperature variations and can be taken as representative of the southeastern part of the Russian Far East and northeast of the China.

To identify the regional representativeness of our reconstruction, we compared it with two temperature reconstructions for surrounding areas (Fig. 1) and a reconstruction for the Northern Hemisphere (Fig. 8). The first reconstruction 
Table 3. Cold and warm periods based on the results of this study compared with other research.

\begin{tabular}{|c|c|c|c|}
\hline Period & $\begin{array}{r}\text { Southern Sikhote-Alin } \\
\text { (this study) }\end{array}$ & $\begin{array}{l}\text { Laobai Mountain } \\
\text { (Lyu et al., 2016) }\end{array}$ & $\begin{array}{r}\text { Changbai Mountains } \\
\text { (Zhu et al., 2009) }\end{array}$ \\
\hline \multirow[t]{8}{*}{ Cold } & $1535-1540^{1} ; 1550-1555^{1}$ & 1 & 1 \\
\hline & 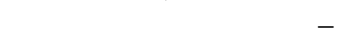 & $1605-1616$ & \\
\hline & $1643-1649 ; 1659-1667$ & $1645-1677$ & 1 \\
\hline & $1675-1689$ & $1684-1691$ & 1 \\
\hline & $1791-1801 ; 1807-1818$ & - & $1784-1815$ \\
\hline & $1822-1827 ; 1836-1852$ & & $1827-1851$ \\
\hline & $1868-1887$ & - & $1878-1889$ \\
\hline & $1911-1925$ & 1911-1924; 1930-1942; 1951-1969 & $1911-1945$ \\
\hline \multirow[t]{8}{*}{ Warm } & $1560-1585^{1}$ & 1 & 1 \\
\hline & $1600-1610^{1} ; 1614-1618$ & - & 1 \\
\hline & $1738-1743$ & - & - \\
\hline & $1756-1759 ; 1776-1781$ & $1767-1785$ & $1750-1783$ \\
\hline & $1787-1793^{2}$ & $1787-1793$ & - \\
\hline & $1795-1807^{2}$ & $1795-1807$ & - \\
\hline & $1855-1865^{2}$ & - & $1855-1877$ \\
\hline & 1944-2014 & 1991-2008 & 1969-2009 \\
\hline
\end{tabular}

${ }^{1}$ The reconstruction not covering this period. ${ }^{2}$ The periods that agree with VUSr but not reliably for VUSr. - Uncertain periods when chronology has EPS >0.75 (AD 1529-1609).

was for summer temperatures in the Northern Hemisphere (Wilson et al., 2016; Fig. 1). The second reconstruction was an April-July tree-ring-based minimum temperature reconstruction for Laobai Mountain (northeastern China), which is approximately $500 \mathrm{~km}$ northwest of our site. The third was a February-April temperature reconstruction for the Changbai Mountains (Zhu et al., 2009; Fig. 1), which are approximately $430 \mathrm{~km}$ southwest of our site. Although the spring and summer temperatures have been reconstructed in the last two cases, we use these reconstructions for comparison because, firstly, there are no other reconstructions for this region, and secondly, despite the possible seasonal shifts, long cold and warm periods should be identified in all seasons.

Cold and warm periods are shown in Table 3 (the duration is given by the authors of the article). The reconstructions show that practically all cold and warm periods coincide but have different durations and intensities. The data on the Northern Hemisphere show considerable overlaps of cold and warm periods, and the correlation between reconstructions is $0.45(p>0.001)$. At the same time, we found a warm period of 1560-1585, which is not clearly shown in the reconstruction for the Northern Hemisphere, though the general trend of temperature change is maintained during this period (Fig. 8). Long cold periods from 1643 to 1667 and from 1675 to 1690 that were revealed for another territory (Lyu et al., 2016; Wilson et al., 2016) coincided with the Maunder Minimum (1645-1715), an interval of decreased solar irradiance (Bard et al., 2000). The coldest year in this study (1662) was revealed in this period too. The Dalton minimum period centered in 1810 is also notable. Interestingly, the cold peri- ods of 1807-1818, 1822-1827, 1836-1852, and 1868-1887 are also registered in reconstructions for Asia (Ohayama et al., 2013) and by Japanese researchers (Fukaishi and Tagami, 1992; Hirano and Mikami, 2007). Moreover, instrumental observations reconstructed for western Japanese territories (the nearest to the study area) provide evidence of a cold period in the 1830s-1880s with a short warm spell in the 1850s (Zaiki et al., 2006), which is in agreement with our data (1855-1865 is not a reliable period; Table 3). For this period, there are contemporaneous records of severe hunger in Japan in 1832 and 1839, which was the result of a summer temperature decrease and rice crop failure (Ohayama et al., 2013).

In this case, the longer cold period for the study area can be explained by the relatively lower influence of the warm current and monsoon and generally colder climate in the south of the Russian Far East compared with Japanese islands.

The differing opinion about the three cold periods in China in the 17th, 18th, and 19th centuries (Wang et al., 2003) is also corroborated by our reconstruction. The cold period in the 19th century is even more pronounced than that reported by Lyu et al. (2016). Moreover, Lyu et al. (2016) corroborate that the ascertained cold period in the 19th century is more evident in southern China, but it is less clear in the northern territories or it has an inverse trend. Although the Russian Far East is further north than the southern Chinese provinces and is closer to the northern part of the country, the marked monsoon climate likely made it possible to reflect the general cold trend in the 19th century, which was typical for both China and the entire Northern Hemisphere. Because of this possi- 

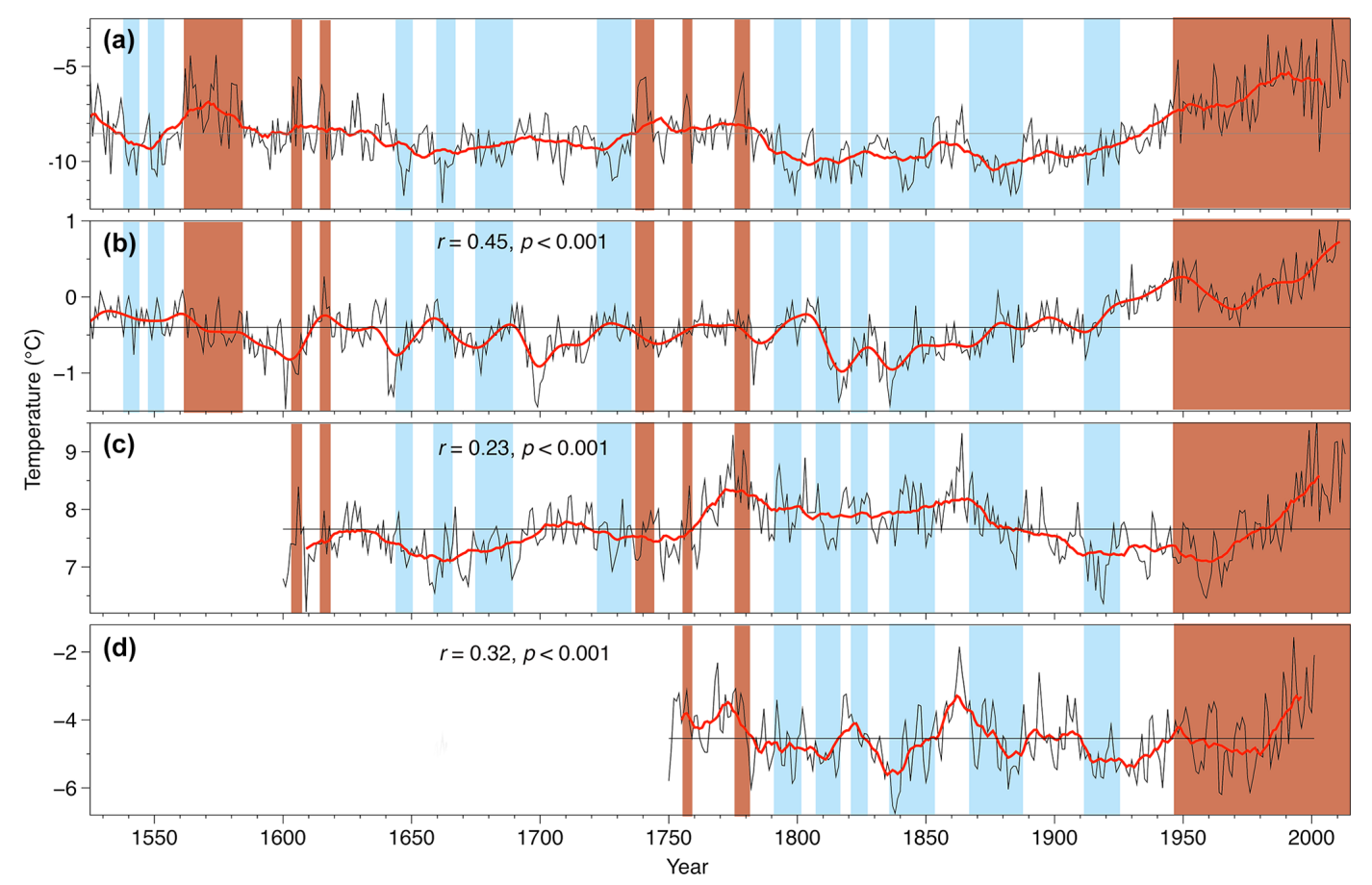

Figure 8. (a) August-December mean minimum temperature reconstructed (VUSr) for the southern part of Sikhote-Alin, (b) Northern Hemisphere extratropical temperature (Wilson et al., 2016), (c) April-July minimum temperature on Laobai Mountain by Lyu et al. (2016), and (d) February-April temperature established by Zhu et al. (2009) in the Changbai Mountains. Black lines denote temperature reconstruction values, and red lines indicate the 21-year moving average; red and blue fields show warm and cold periods, respectively (in this study).

ble explanation, the cold period in the 19th century for the Changbai Mountains shows up more distinctly than for the northern and western territory of Laobai Mountain (Fig. 8).

Apparently, this discrepancy in regional climate flow is the reason that our reconstruction agrees well with the general reconstruction for the whole hemisphere $(r=0.45$, $p<0.001)$ and to a lesser extent agrees with the regional curves for Laobai Mountain $(r=0.23, p<0.001)$ and the Changbai Mountains $(r=0.32, p<0.001)$.

The changing dynamics of 20th century temperature are also interesting to watch. The comparison of the minimum annual temperatures for the territory and the reconstructed data for the period of 1960-2003 show significant data correlation (Fig. 7), including for the northeastern part of China. At the same time, for Chinese territory (both for southwestern regions and for more northwestern regions), the warming is apparent only in the last quarter century (Zhu et al., 2009) or at the end of the 20th century (Lyu et al., 2016; Fig. 8c, $d$ in this paper). This trend, revealed for the southern Sikhote-Alin Mountains (a warm spell since 1944), is corroborated for the whole Northern Hemisphere (Wison et al., 2016; Fig. 8a, b in this paper). The maximum cold period is also corroborated, which we note for the 19th century (Fig. 8a, b).

The probable explanation is in the regional climate flow differences in the compared data. The territory of northeast- ern China is more continental, though the influence of the Pacific Ocean is also notable. At the same time, the southern part of the Sikhote-Alin Mountains is more prone to the influence of monsoons, as are the Japanese islands. According to paleoreconstructions, the Little Ice Age occurred in the Northern Hemisphere 600-150 years ago (Borisova, 2014). The period of landscape formation (vegetation types and altitudinal zonation) for the Sikhote-Alin range during the transition from the Little Ice Age to contemporary conditions occurred within the last 230 years (Razzhigaeva et al., 2016). The timeframe of the Little Ice Age is generally recognized as varying considerably depending on the region (Bazarova et al., 2014). However, it is certain that the Little Ice Age is accompanied by an increase in humidity in coastal areas of northeastern Asia (Bazarova et al., 2014). Thus, in conditions similar to on the Japanese islands, the Little Ice Age was accompanied by lingering and intensive rains (Sakaguchi, 1983), and the last typhoon activity was registered for the Japanese islands from the middle of the 17th century to the end of the 19th century (Woodruff et al., 2009). At the same time, the reconstruction of climatic changes for the whole territory of China for the last 2000 years (Ge et al., 2016) shows that the cold period lasted until 1920, which correlates with the data we obtained. This timespan wholly coincides with our data, and we can draw the conclusion that 
in the southern region of the Sikhote-Alin Mountains, the Little Ice Age ended at the turn of the 19th century.

Unfortunately, when comparing temperature, different changes were also observed for some cold and warm years (Fig. 8). This finding may be attributed to differences in the reconstructed temperature parameters (such as average value, minimum temperature, and maximum temperature) and environmental conditions in different sampling regions. Recent studies show that the oscillations in the medium, minimum, and maximum temperature are often asymmetrical (Karl et al., 1993; Xie and Cao, 1996; Wilson and Luckman, 2002, 2003; Gou et al., 2008). The global warming over the past few decades has been mainly caused by the rapid increase in nighttime or minimum temperatures but not maximum temperatures. Meanwhile, some differences between the reconstructed temperature values were well explained by a comparison with similar areas.

We can conclude that the analysis shows that the reconstructed data are representative for large-scale regional temperature variations (Fig. 7). At the same time, some cold and warm periods in our reconstruction and other neighbored studies do not coincide (Fig. 8), which can be due to the reconstruction of other climatic parameters and differing environmental conditions. Thus, we believe that these results can characterize regional climate variations and provide reliable data for large-scale reconstructions for the northeastern portion of Eurasia, but their use for large-scale regional reconstructions requires further research.

\subsection{Periodicity of climatic changes and their links to global climate processes}

Among the significant periodicities in the reconstructed temperature detected by the MTM analysis (Fig. 7), some peaks were singled out: 2.3-year (95\%), 2.5-year (99\%), 2.9-year (99\%), 3.0-year (99\%), 3.3-year (95\%), 3.7-year (95\%), and 8.9-year (99\%) short periods and 20.4-year (95\%), 47.6year $(95 \%)$, and 188.7-year (99\%) long periods. SSA analysis shows significance near-3-year, 9-year, 20.4-year, and 200-year periods.

The 3-year cycle may be linked with El Niño-Southern Oscillation (ENSO). These high-frequency (2-7 years) cycles (Bradley et al., 1987) have also been found in other treering-based temperature reconstructions in northeastern Asia (Zhu et al., 2009; Li and Wang, 2013; Zhu et al., 2016; Gao et al., 2015). The 2-3-year quasi-cycles may also correspond to the quasi-biennial oscillation (Labitzke and van Loon, 1999) and the tropospheric biennial oscillation (Meehl, 1987). Despite the fact that many authors establish linkage between 2- to 7-year cycles and ENSO or quasi-biennial oscillation in northeastern Asia, we could not find significant correlation between the August-December minimum temperature reconstruction and Nino3, but the analysis showed significant correlation between the reconstruction and the temperature of Northern Hemisphere oceans. This probably means that the temperature variations are more associated with the influence of the PDO than ENSO.

On the decadal timescale, analysis showed 20-year cycles that may reflect processes influenced by PDO (Mantua and Hare, 2002) variability, which has been found at cycles of 15-25 and 50-70 years (Ma, 2007). Our analysis shows a significant correlation $(r=0.68, p<0.0001)$ between reconstruction and the mean annual PDO index of Mann et al. (2009) from 1900 to 2000. Taking into account that many researchers, who studied the territory of northeastern Asia, have also revealed these cycles in relation to the Korean pine, we hypothesize that the Korean pine tree ring series support the concept of long-term, multi-decadal variations in the $\mathrm{Pa}$ cific (e.g., D'Arrigo et al., 2001; Cook, 2002; Jacoby et al., 2004; Liu et al., 2009; Li and Wang, 2013; Willes et al., 2014; $\mathrm{Lu}, 2016$ ) and that such variation or shifts have been present in the Pacific for several centuries. The PDO is a main index of major variations in the North Pacific climate and ocean productivity (Mantua et al., 1997; Jacoby et al., 2004). In particular, according to instrumental data analysis (Shatilina and Anzhina, 2008), the last warming of the northern part of the Pacific Ocean (since the 1970s) resulted in an intensive temperature increase and precipitation decrease in the southern part of the Russian Far East.

We suppose that a 9-year cycle may be related to solar activity, as, first of all, many authors showed influence of solar activity on the climate variability (Bond et al., 2001; Lean and Rind, 1999; Lean, 2000; Mann et al., 2009; Zhu et al., 2016). Secondly, the significant correlation between of the August-December minimum temperature reconstruction and TSI can be regarded as additional evidence of this assumption. Finally, there is a coincidence of the reconstructed cold periods with the Maunder Minimum (1645-1715) and the Dalton minimum period centered in 1810 . The solar activity influence in the region is traditionally associated with an indirect effect on the circulation of the atmosphere (Erlykin et al., 2009; Fedorov et al., 2015). In the second half of the 20th century the solar radiation intensity changes contributed to more intensive warming of the equatorial part of the Pacific Ocean and more active inflow of warm air masses to the north (Fedorov et al., 2015).

Despite the fact that it is quite difficult to reveal for certain long-period cycles in a 486-year chronology, we nonetheless revealed the 189-year cycle (MTM) or 200-year cycle (SSA analysis), which probably may possibly be linked to the solar activity. Close periodicity is revealed in long-term climate reconstructions and is linked to the quasi-200-year solar activity cycle in other studies (Raspopov et al., 2008, 2009). Raspopov et al. (2008) showed that in tree-ring-based reconstructions the cycle varies from 180 to 230 years. Moreover, the high correlation between the minimum temperature reconstructions and TSI, and also the revealed link between the reconstructed temperatures and solar activity minima, lead us to suppose that the solar activity may be the driver of the 200-year cycle. Such climate cycling, linked not only to 
temperature but also to precipitation, is revealed for the territories of Asia, North America, Australia, the Arctic, and the Antarctic (Raspopov et al., 2008). At the same time, the 200-year cycle (de Vries cycle) may often have a phase shift from some years to decades and correlates not only positively but also negatively with climatic fluctuations depending on the character of the nonlinear response of the atmosphereocean system within the scope of the region (Raspopov et al., 2009). According to Raspopov et al. (2009), the study area is in the zone that reacts with a positive correlation to solar activity, though the authors note that we should not expect a direct response because of the nonlinear character of the atmosphere-ocean system reaction to variability in solar activity (Raspopov et al., 2009). Taking into consideration this fact and that the cold and warm periods shown in our reconstruction are slightly shifted compared with more continental areas and the whole Northern Hemisphere, we can say that the reconstruction of minimum August-December temperatures reflects the global climate change process in aggregate with the regional characteristics of the study area.

\section{Conclusions}

Using the tree ring width of Pinus koraiensis, the mean minimum temperature of the previous August-December has been reconstructed for the southern part of the SikhoteAlin Mountains, northeastern Asia, and Russia, for the past 486 years. This data set is the first climate reconstruction for this region, and for the first time for northeastern Asia, we present a reconstruction with a length exceeding 486 years.

Because explained variance in our reconstruction is about $39 \%$, we believe that the result is noteworthy as it displays the respective temperature fluctuations for the whole region, including northeastern China, the Korean peninsula, and the Japanese archipelago. Our reconstruction is also in good agreement with the climatic reconstruction for the whole Northern Hemisphere. The reconstruction shows good agreement with the cold periods described by documentary notes in eastern China and Japan. All these comparisons prove that for this region, the climatic reconstruction based on tree ring chronology has a good potential to provide a proxy record for long-term, large-scale past temperature patterns for northeastern Asia. The results show the cold and warm periods in the region, which are conditional on global climatic processes (PDO) and may reflect the influence of solar activity (the 9-11-year and 200-year solar activity cycles). At the same time, the reconstruction highlights the peculiarities of the flows of global process in the study area and helps in understanding the processes in the southern territory of the Russian Far East for more than the past 450 years. Undoubtedly, the results of our research are important for studying the climatic processes that have occurred in the study region and in all of northeastern Asia and for situating them within the scope of global climatic change.
Data availability. The August-December minimum temperature reconstruction on Southern Sikhote-Alin Mountain Range is available in the Supplement of the original publication and all the data published in this study are available for noncommercial scientific purposes.

\section{The Supplement related to this article is available online at https://doi.org/10.5194/cp-14-57-2018-supplement.}

Competing interests. The authors declare that they have no conflict of interest.

Acknowledgements. This work was funded by the Russian Foundation for Basic Research, project 15-04-02185.

Edited by: Marit-Solveig Seidenkrantz

Reviewed by: three anonymous referees

\section{References}

Allen, M. R. and Smith, L. A.: Monte Carlo SSA: Detecting irregular oscillations in the Presence of Colored Noise, J. Climate, 9, 3373-3404, https://doi.org/10.1175/15200442(1996)009<3373:MCSDIO>2.0.CO;2, 1996.

Anchukaitis, K. J., D’Arrigo, R. D., Andreu-Hayles, L., Frank, D., Verstege, A., Curtis, A., Buckley, B. M., Jacoby, G. C., and Cook, E. R.: Tree-ring-reconstructed summer temperatures from Northwestern North America during the last nine centuries, J. Climate, 26, 3001-3012, https://doi.org/10.1175/JCLI-D-1100139.1, 2013.

Bard, E., Raisbeck, G., Yiou, F., and Jouzel, J.: Solar irradiance during the last 1200 years based on cosmogenic nuclides, Tellus B, 52, 985-992, 2000.

Bazarova, V. B., Grebennikova, T. A., and Orlova, L. A.: Natural-environment dynamic within the Amur basin during the neoglacial, Geogr. Nat. Resour., 35, 275-283, https://doi.org/10.1134/S1875372814030111, 2014.

Bond, G., Kromer, B., Beer, J., Muscheler, R., Evans, M. N., Showers, W., Hoffmann, S., Lotti-Bond, R., Hajdas, I., and Bonani, G.: Persistent solar influence on north Atlantic climate during the Holocene, Science, 294, 2130-2136, 2001.

Borisova, O. K.: Landscape-climatic changes in Holocene, Reg. Res. Rus., 2, 5-20, 2014.

Bradley, R. S., Diaz, H. F., Kiladis, G. N., and Eischeid, J. K.: ENSO signal in continental temperature and precipitation records, Nature, 327, 497-501, 1987.

Dettinger, M. D., Ghil, M., Strong, C. M., Weibel, W., and Yiou, P.: Software expedites singular-spectrum analysis of noisy time series, EOS T. Am. Geophys. Un., 76, https://doi.org/10.1029/EO076i002p00012, 1995.

Cook, E. R.: Reconstructions of Pacific decadal variability from long tree-ring records, Eos Trans. 83 (19) Spring Meet. Suppl., Abstract GC42A-04, 2002. 
Cook, E. R. and Kairiukstis, L. A.: Methods of dendrochronology: applications in the environmental sciences, Kluwer Academic Publishers, Dordrecht, 394 pp., 1990.

Corona, C., Guiot, J., Edouard, J. L., Chalié, F., Büntgen, U., Nola, P., and Urbinati, C.: Millennium-long summer temperature variations in the European Alps as reconstructed from tree rings, Clim. Past, 6, 379-400, https://doi.org/10.5194/cp-6-379-2010, 2010.

Dai, L. M., Qi, L., Su, D. K., Wang, Q. W., Ye, Y. J., and Wang, Y.: Changes in forest structure and composition on Changbai Mountain in Northeast China, Ann. Forest Sci., 68, 889-897, 2011.

D'Arrigo, R., Villalba, R., and Wiles, G.: Tree-ring estimates of Pacific decadal climate variability, Clim. Dynam., 18, 219-224, https://doi.org/10.1007/s003820100177, 2001.

Ding, Y. and Dai, X.: Temperature Variation in China during the Last 100 years, Meteorology, 20, 19-26, 1994.

Efron, B.: Bootstrap methods: another look at the jackknife, Ann. Stat., 7, 1-26, 1979.

Erlykin, A. D., Sloan, T., and Wolfendale, W.: Solar activity and the mean global temperature, Environ. Res. Lett., 4, 014006, https://doi.org/10.1088/1748-9326/4/1/014006, 2009.

Fedorov, V. M., Kononova, N. K., Gorbunov, R. V., and Gorbunova, T. Y.: Solar radiation and circulation processes in the atmosphere of the Northern Hemisphere, The complex systems, 1, 58-71, 2015.

Fritts, H. C.: Tree rings and climate, Academic Press Inc., London, 567 pp., 1976.

Fukaishi, K. and Tagami, Y.: An attempt of reconstructing the winter weather situations from $1720-1869$ by the use of historical documents, in: Proceedings of the International Symposium on the Little Ice Age Climate, Department of Geography, Tokyo Metropolitan University, Tokyo, 194-201, 1992.

Gao, L., Gou, X., Deng, Y., Yang, M., Zhang, F., and Li, J.: Dendroclimatic reconstruction of temperature in the eastern Qilian Mountains, northwestern China, Clim. Res., 62, 241-250, https://doi.org/10.3354/cr01271, 2015.

Ge, Q., Zheng, J., Hao, Z., Liu, Y., and Li, M.: Recent advances on reconstruction of climate and extreme events in China for the past 2000 years, J. Geogr. Sci., 26, 827-854, https://doi.org/10.1007/s11442-016-1301-4, 2016.

Ghil, M., Allen, R. M., Dettinger, M. D., Ide, K., Kondrashov, D., Mann, M. E., Robertson, A., Saunders, A., Tian, Y., Varadi, F., and Yiou, P.: Advanced spectral methods for climatic time series, Rev. Geophys., 40, 3.1-3.41, https://doi.org/10.1029/2000RG000092, 2002.

Gou, X., Chen, F., Yang, M., Gordon, J., Fang, K., Tian, Q., and Zhang, Y.: Asymmetric variability between maximum and minimum temperatures in Northeastern Tibetan Plateau: evidence from tree rings, Sci. China. Ser. D, 51, 41-55, 2008.

Hirano, J. and Mikami, T.: Reconstruction of winter climate variations during the 19th century in Japan, Int. J. Climatol., 28, 1423 1434, https://doi.org/10.1002/joc.1632, 2007.

Holmes, R. L.: Computer-assisted quality control in tree-ring dating and measurement, Tree-Ring Bull., 43, 69-78, 1983.

Ishikawa, Y., Krestov, P. V., and Namikawa, K.: Disturbance history and tree establishment in old-growth Pinus koraiensis-hardwood forests in the Russian Far East, J. Veg. Sci., 10, 439-448, 1999.

Ivanov, G. I.: Soils of Primorsky Kray (Russia), [Pochvi Primorskogo kraya], 107, 1964 (in Russian).
Jacoby, G., Solomina, O., Frank, D., Eremenko, N., and D'Arrigo, R. D.: Kunashir (Kuriles) Oak 400-year reconstruction of the temperature and relation to the Pacific Decadal Oscillation, Palaeogeogr. Palaeocl., 2009, 303-311, https://doi.org/10.1016/j.palaeo.2004.02.015, 2004.

Karl, T. R., Jones, P. D., Knight, R. W., Kulas, G., Plummer, N., Razuvayev, V., Gallo, K. P., Lindseay, J., Charlson, R. J., and Peterson, T. C.: A new perspective on recent global warming: asymmetric trends of daily maximum and minimum temperature, B. Am. Meteorol. Soc., 74, 1007-1023, 1993.

Kolesnikov, B. P.: Korean pine forests of the [Russian] Far East, Trudy DVF AN SSSR, 2, 1-264, 1956 (in Russian).

Körner, C. and Paulsen, J.: A world-wide study of high altitude treeline temperatures, J. Biogeogr., 31, 713-732, https://doi.org/10.1111/j.1365-2699.2003.01043.x, 2004.

Kozhevnikova, N. K.: Dynamics of weather-climatic characteristics and ecological function of small river basin, Sib. Ecol. J., 5, 93 703, 2009 (in Russian).

Kress, A., Hangartner, S., Bugmann, H., Büntgen, U., Frank, D. C., Leuenberger, M., Siegwolf, R. T. W., and Saurer, M.: Swiss tree rings reveal warm and wet summers during medieval times, Geophys. Res. Lett., 41, 1732-1737, https://doi.org/10.1002/2013GL059081, 2014.

Labitzke, K. G. and van Loon, H.: The Stratosphere: Phenomena, History and Relevance, Springer, Berlin, 179 pp., 1999.

Lean, J.: Evolution of the Sun's spectral irradiance since the Maunder Minimum, Geophys. Res. Lett., 27, 2425-2428, https://doi.org/10.1029/2000GL000043, 2000.

Lean, J. and Rind, D.: Evaluating sun-climate relationships since the Little Ice Age, J. Atmos. Sol.-Terr. Phy., 61, 25-36, 1999.

Li, M. and Wang, X.: Climate-growth relationships of three hardwood species and Korean pine and minimum temperature reconstruction in growing season in Dunhua, China, J. Nanjing. For. Univ., 37, 29-34, 2013.

Liu, Q. J.: Structure and dynamics of the subalpine coniferous forest on Changbai mountain, China, Plant. Ecol., 132, 97-105, 1997.

Liu, Y., Bao, G., Song, H., Cai, Q., and Sun, J.: Precipitation reconstruction from Hailar pine (Pinus koraiensis var. mongolica) tree rings in the Hailar region, Inner Mongolia, China back to 1865 AD, Paleogaeogr. Palaeocl., 282, 81-87, https://doi.org/10.1016/j.palaeo.2009.08.012, 2009.

Lu, R., Jia, F., Gao, S., Shang, Y., and Chen, Y.: Tree-ring reconstruction of January-March minimum temperatures since 1804 on Hasi Mountain, northwestern China, J. Arid. Environ., 127, 66-73, https://doi.org/10.1016/j.jaridenv.2015.10.020, 2016.

Lyu, S., Li, Z., Zhang, Y., and Wang, X.: A 414-year tree-ring-based April-July minimum temperature reconstruction and its implications for the extreme climate events, northeast China, Clim. Past 12, 1879-1888, https://doi.org/10.5194/cp-12-1879-2016, 2016.

Ma, Z. G.: The interdecadal trend and shift of dry/wet over the central part of north China and their relationship to the Pacific Decadal Oscillation (PDO), Chinese Sci. Bull., 52, 2130-2139, 2007.

Mann, M. E. and Lees, J. M.: Robust estimation of background noise and signal detection in climatic time series, Clim. Change, 33, 409-445, 1996.

Mann, M. E., Zhang, Z., Rutherford, S., Bradley, R. S., Hughes, M., Shindell, D., Amman, C., Faluvegi, G., and Ni, F.: Global Signatures and Dinamical Origins of the Little Ice 
Age and Medieval Climate Anomaly, Science, 326, 1256-1260, https://doi.org/10.1126/science.1177303, 2009.

Mantua, N. and Hare, S.: The Pacific decadal oscillation, J. Oceanogr., 58, 35-44, 2002.

Mantua, N., Hare, S., Zhang, Y., Wallace, J., and Francis, R.: A Pacific interdecadal climate oscillation with impacts on salmon production, B. Am. Meteorol. Soc., 78, 1069-1080, https://doi.org/10.1175/15200477(1997)078<3C1069:APICOW>3E2.0.CO;2, 1997.

Meehl, G. A.: The annual cycle and interannual variability in the tropical Pacific and Indian Ocean regions, Mon. Weather Rev., 115, 27-50, 1987.

Melvin, T. M. and Briffa, K. R.: A "signal-free" approach to dendroclimatic standardisation, Dendrochronologia, 26, 71-86, https://doi.org/10.1016/j.dendro.2007.12.001, 2008.

Ohyama, M., Yonenobu, H., Choi, J.-N., Park, W.-K., Hanzawa, M., and Suzuki, M.: Reconstruction of northeast Asia spring temperature 1784-1990, Clim. Past, 9, 261-266, https://doi.org/10.5194/cp-9-261-2013, 2013.

Omelko, A., Ukhvatkina, O., and Zmerenetsky, A.: Disturbance history and natural regeneration of an old-growth Korean pine-broadleaved forest in the Sikhote-Alin mountain range, Southeastern Russia, Forest Ecol. Manag., 360, 221-234, https://doi.org/10.1016/j.foreco.2015.10.036, 2016.

Omelko, A. M. and Ukhvatkina, O. N.: Characteristics of gapdynamics of conifer-broadleaved forest of Southen Sikhote-Alin (Russia), Plant World Asian Russ., 1, 106-113, 2012.

Popa, I. and Bouriaud, O.: Reconstruction of summer temperatures in Eastern Carpathian Mountain (Rodna Mts, Romania) back to AD 1460 from tree-rings, Int. J. Climatol., 34, 871-880, https://doi.org/10.1002/joc.3730, 2014.

Porter, T. J., Pisaric, M. F., Kokelj, S. V., and DeMontigny, P.: A ring-width-based reconstruction of June-July minimum temperatures since AD 1245 from white spruce stands in the Mackenzie Delta region, northwestern Canada, Quaternary Res., 80, 167179, https://doi.org/10.1016/j.yqres.2013.05.004, 2013.

Raspopov, O. M., Dergachev, V. A., Esper, J., Kozyreva, O. V., Frank, D., Ogurtsov, M., Kolström, T., and Shao, X.: The influence of the de Vries ( 200-year) solar cycle on climate variations: Results from the Central Asian Mountains?and their global link, Palaeogeogr. Palaeocl., 259, 6-16, https://doi.org/10.1016/j.palaeo.2006.12.017, 2008.

Raspopov, O. M., Dergachev, V. A., Kozyreva, O. V., Kolström, T., Lopatin, E. V., and Luckman, B.: Geography of 200-year climate periodicity and Lon-Term Variations of Solar activity, Reg. Res. Russ., 2, 17-27, 2009.

Razzhigaeva, N. G., Ganzei, L. A., Mokhova, L. M., Makarova, T. R., Panichev, A. M., Kudryavtseva, E. P., Arslanov, K. A., Maksimov, F. E., and Starikova, A. A.: The Development of Landscapes of the Shkotovo Plateau of SikhoteAlin in the Late Holocene, Reg. Res. Russ., 3, 65-80, https://doi.org/10.15356/0373-2444-2016-3-65-80, 2016.

Ren, F. and Zhai, P.: Study on Changes of China's Extreme Temperatures During 1951-1990, Sci. Atmos. Sin., 22, 217-227, 1998.

Sakaguchi, Y.: Warm and cold stages in the past 7600 years in Japan and their global correlation, Bull. Dep. Geogr., 15, 1-31, 1983.

Shan, K. S., Touchan, R., Babushkina, E., Shishov, V. V., Meko, D. M., Abramenko, O. V., Belokopytova, L. V., Hordo, M., Jevesenak, J., Kedziora, W., Kostyakova, T. V., Moskwa, A., Saikia, A.,
Zsewastynowicz, L., Sidenko, T., Srrantsov, A., Tamkeviciute, M., Tomusiak, R., and Tychkov, I.: August to July precipitation from tree rings in the forest-steppe zone of central Siberia (Russia), Tree-reng res., 71, 37-44, https://doi.org/10.3959/15361098-71.1.37, 2015

Shao, X. and $\mathrm{Wu}, \mathrm{X}$.: Reconstruction of climate change on Changbai Mountain, Northeast China using tree-ring data, Quaternary Sci., 1, 76-83, 1997.

Shatilina, T. A. and Anzhina, G. I.: Features of atmospheric circulation and climate in the Far East (Russia) in the beginning of 21 Century, Izv. TINRO, 152, 225-239, 2008 (in Russian).

Stokes, M. A. and Smiley, T. L.: Tree-ring dating, The University of Chicago Press, Chicago, London, 73 pp., 1968.

Tang, H., Zhai, P., and Wang, Z.: On Change in Mean Maximum Temperature, Minimum Temperature and Diurnal Range in China During 1951-2002, Climatic Environ. Res., 10, 728-735, 2005.

Thapa, U. K., Shan, S. K., Gaire, N. P., and Bhuju, D. R.: Spring temperatures in the far-western Nepal Himalaya since 1640 reconstructed from Picea smithiana tree-ring widths, Clim. Dynam., 45, 2069-2081, https://doi.org/10.1007/s00382-014-2457$1,2015$.

Wang, H., Shao, X. M., Jiang, Y., Fang, X. Q., and Wu, S. W.: The impacts of climate change on the radial growth of Pinus koraiensis along elevations of Changbai Mountain in northeastern China, Forest Ecol. Manag., 289, 333-340, https://doi.org/10.1016/j.foreco.2012.10.023, 2013.

Wang, S., Liu, J., and Zhou, J.: The Climate of Little Ice Age Maximum in China, J. Lake. Sci., 15, 369-379, 2003.

Wang, W., Zhang, J., Dai, G., Wang, X., Han, S., Zhang, H., and Wang, Y.: Variation of autumn temperature over the past 240 years in Changbai Mountain of Northeast China: A reconstruction with tree-ring records, China. J. Ecol., 31, 787-793, 2012.

Wang, X., Zhang, M., Ji, Y., Li, Z., Li, M., and Zhang, Y.: Temperature signals in tree-ring width and divergent growth?of Korean pine response to recent climate warming in northeast Asia, Trees, 31, 415-427, https://doi.org/10.1007/s00468-015-1341-x, 2016.

Wang, Z., Ding, Y., He, J., and Yu, J.: An updating analysis of the climate change in China in recent 50 years, Acta Meteorol. Sin., 62, 228-236, 2004.

Woodruff, J. D., Donnelly, J. P., and Okusu, A.: Exploring typhoon variability over the mid-to-late Holocene: evidence of extreme coastal flooding from Kamikoshiki, Japan, Quaternary Sci. Rev. 28, 1774-1785, https://doi.org/10.1016/j.quascirev.2009.02.005, 2009.

Wigley, T. M. L., Briffa, K. R., and Jones, P. D.: On the average value of correlated time series, with applications in dendroclimatology and hydrometeorology, J. Clim. Appl. Meteorol., 23, 201-213, 1984.

Wiles, G. C., Solomina, O., D’Arrigo, R., Anchukaitis, K. J., Gensiarovsky, Y. V., and Wiesenberg, N.: Reconstructed summer temperatures over the last 400 year a based on larch ring widths: Sakhalin Island, Russian Far East, Clim. Dynam., 45, 397-405, https://doi.org/10.1007/s00382-014-2209-2, 2014.

Wilson, R., Anchukaitis, K., Briffa, K. R., Büntgen, U., Cook, E., D’Arrigo, R., Davi, N., Esper, J., Frank, J., Gunnarson, B., Hegel, G., Helama, S., Klesse, S., Krusic, P. J., Linderholm, H. W., Myglan, V., Osborn, T. J., Rydval, M., Schneider, L., Schurer, A., Wiles, G., Zhang, P., and Zorita E.: Last millen- 
nium northern hemishere summer temperatures from tree rings: Part I: The long term context, Quaternary Sci. Rev., 134, 1-18, https://doi.org/10.1016/j.quascirev.2015.12.005, 2016.

Wilson, R. J. S. and Luckman, B. H.: Tree-ring reconstruction of maximum and minimum temperatures and the diurnal temperature range in British Columbia, Canada, Dendrochronologia, 20, $1-12,2002$.

Wilson, R. J. S. and Luckman B. H.: Dendroclimatic reconstruction of maximum summer temperatures from upper treeline sites in Interior British Columbia, Canada, Holocene, 13, 851-861, https://doi.org/10.1191/0959683603hl663rp, 2003.

Xie, Z. and Cao, H.: Asymmetric changes in maximum and minimum temperature in Beijing, Theor. Appl. Climatol., 55, 151156, 1996

Yin, H., Guo, P., Liu, H., Huang, L., Yu, H., Guo, S., and Wang, F.: Reconstruction of the October mean temperature since 1796 at Wuying from tree ring data, Adv. Clim. Change. Res., 5, 18-23, 2009.

Yin, H., Liu, H., Linderholm, H. W., and Sun Y.: Tree ring densitybased warm-season temperature reconstruction since AD 1610 in the eastern Tibetan Plateau, Palaeogeogr. Palaeoecl., 426, 112120, https://doi.org/10.1016/j.palaeo.2015.03.003, 2015.

Young, G. A.: Bootstrap: more than a stab in the dark, Stat. Sci., 9, 382-415, 1994.

Zaiki, M., Können, G., Tsukahara, T., Jones, P., Mikami, T., and Matsumoto, K.: Recovery of nineteenth-century Tokyo/Osaka meteorological data in Japan, Int. J. Climatol., 26, 399-423, https://doi.org/10.1002/joc.1253, 2006.
Zang, C. and Biondi, F.: Treeclim: an R package for the numerical calibration of proxy-climate relationships, Ecography, 38, 001006, https://doi.org/10.1111/ecog.01335, 2015.

Zhang, R. B., Yuan, Y. J., Wei, W. S., Gou, X. H., Yu, S. L., Shang, H. M., Chen, F., Zhang, T. W., and Qin, L.: Dendroclimatic reconstruction of autumn-winter mean minimum temperature in the eastern Tibetan Plateau since 1600 AD, Dendrochronologia, 33, 1-7, https://doi.org/10.1016/j.dendro.2014.09.001, 2015.

Zhao, C., Ring, G., Zhang, Y., and Wang, Y.: Climate change of the Northeast China over the past 50 years, J. Arid. Land. Resour. Environ., 23, 25-30, 2009.

Zhu, H. F., Fang, X. Q., Shao, X. M., and Yin, Z. Y.: Tree ring-based February-April temperature reconstruction for Changbai Mountain in Northeast China and its implication for East Asian winter monsoon, Clim. Past, 5, 661-666, https://doi.org/10.5194/cp-5661-2009, 2009.

Zhu, L., Li, S., and Wang, X.: Tree-ring reconstruction of February-March mean minimum temperature back to $1790 \mathrm{AD}$ in Yichun, Northeast China, Quaternary Sci., 35, 1175-1184, https://doi.org/10.11928/j.issn.1001-7410.2015.05.13, 2015.

Zhu, L., Li, Z., Zhang, Y., and Wanga, X.: A 211-year growing season temperature reconstruction using tree-ring width in Zhangguangcai Mountains, Northeast China: linkages to the Pacific and Atlantic Oceans, Int. J. Climatol., 37, 3145-3153, https://doi.org/10.1002/joc.4906, 2016. 